\title{
Pemanfaatan Karbon Aktif Dari Limbah Kulit Pisang Goroho (Musa acuminafe) Sebagai Adsorben Zat Pewarna Tekstil Methylene Blue
}

\author{
Anita Lantanga*, Jemmy Abidjulua , Henry F. Aritonanga \\ aJurusan Kimia, FMIPA, Unsrat, Manado
}

KATA KUNCI

Karbon Aktif

Kulit Pisang Goroho

Methylene Blue

\begin{abstract}
A B S TR A K
Penelitian ini bertujuan untuk membuat karbon aktif kulit pisang Goroho yang teraktivasi $\mathrm{H}_{2} \mathrm{SO}_{4}$ dan $\mathrm{NaOH}$ yang mampu menyerap zat warna Methylene Bluedan menentukan jenis aktivator, waktu kontak dan massa optimumnya. Karbon aktif kulit pisang Goroho dibuat dengan mengkarbonisasi kulit pisang Goroho kering yang diaktivasi dengan $\mathrm{H}_{2} \mathrm{SO}_{4}$ dan $\mathrm{NaOH}$. Jenis aktivator, waktu kontak dan massa optimumnya ditentukan berdasarkan persentase penyerapan Methylene Blue tertinggi. Hasil penelitian menunjukan persentase penyerapan tertinggi pada massa 0,10 gram dan waktu kontak 90 menit. Persentase penyerapan zat pewarna Methylene Blue oleh karbon aktif kulit pisang Goroho yang teraktivasi $\mathrm{H}_{2} \mathrm{SO}_{4}$ yang diperoleh lebih tinggi dibandingkan karbon aktif kulit pisang Goroho yang teraktivasi $\mathrm{NaOH}$.

A B S T R A C T

This study is intended to make activated banana activated Goroho banana peels $\mathrm{H}_{2} \mathrm{SO}_{4}$ and $\mathrm{NaOH}$ capable of absorbing Methylene Blue dyes and determine the type of activator, contact time and optimum mass. The Goroho banana bark activated carbons are made by carbonizing the skin of dried Goroho bananas that are activated with $\mathrm{H}_{2} \mathrm{SO}_{4}$ and $\mathrm{NaOH}$. The type of activator, contact time and optimum mass are determined by the highest percentage of Methylene Blue absorption. The results showed the highest absorption percentage at mass of 0.10 gram and contact time 90 minutes. Percentage absorption of methylene blue dye by Activated $\mathrm{H}_{2} \mathrm{SO}_{4}$ Goroho activated banana peel activated carbon from activated $\mathrm{NaOH}$ activated $\mathrm{NaOH}$ activated Goroho banana skin.
\end{abstract}

K E Y W O R D S

Activated Carbon

Goroho Banana Peels

Methylene Blue
TERSEDIA ONLINE

1 Agustus 2017

1. Pendahuluan

Tanaman pisang merupakan tanaman yang banyak dijumpai di Indonesia. Buah pisang sendiri merupakan salah satu buah yang digemari oleh masyarakat karena kandungan gizi-nya yang tinggi dan paling mudah dijumpai di pasar-pasar tradisional maupun pasar-pasar swalayan. Di Indonesia, terdapat berbagai jenis tanaman pisang yang kebanyakan merupakan tanaman khas dari suatu daerah. Pisang Goroho (Musa acuminafe) merupakan salah satu jenis tanaman pisang khas di Sulawesi Utara. Menurut Alhabsyi et al. (2014), penggunaan pisang Goroho, umumnya dijadikan pisang goreng, pisang rebus dan kripik. Pisang Goroho biasanya disajikan pada saat akan minum kopi pagi, sore hari setelah melakukan pekerjaan. Namun, kulitnya belum banyak dimanfaatkan oleh masyarakat Indonesia khususnya Sulawesi Utara dan hanya dibuang begitu saja.

Kulit pisang merupakan bahan buangan atau limbah buah pisang yang cukup banyak jumlahnya. Umumnya digunakan sebagai makanan ternak seperti kambing, sapi dan kerbau. Jumlah dari kulit pisang cukup banyak yaitu sekitar 1/3 dari buah pisang yang belum dikupas. Kulit pisang juga menjadi salah satu limbah dari industri pengolahan pisang, namun bisa dijadikan teknologi dalam penjernihan air (Lubis, 2012).

Menurut Pankaj et al. (2012) dan Fitriani et al. (2015), kulit pisang dapat dimanfaatkan sebagai pengadsorpsi zat warna. Pada penelitian tersebut, 
kulit pisang dipanaskan secara langsung sebagai adsorben untuk Reactive Red 141 dan Methylene Blue. Hasil penelitian ini menunjukan bahwa massa adsorben, waktu kontak antara kulit pisang dengan bahan yang akan dijerap memegang peran yang sangat penting untuk mendapatkan massa adsorben dan waktu kontak terbaik. Namun demikian, penelitian ini tidak mengubah kulit pisang menjadi karbon aktif. Selain itu, Darmayanti et al. (2012) juga telah memanfaatkan kulit pisang Kepok yang telah diubah menjadi karbon aktif dan digunakan sebagai adsorben untuk mengadsorpsi logam timbal $(\mathrm{Pb})$ dan seng (Zn). Penelitian tersebut mengaktivasi karbon aktifnya menggunakan larutan $\mathrm{NaOH}$.

Karbon aktif merupakan adsorben yang baik untuk pemurnian, menghilangkan warna dan bau, deklorinasi, detoksifikasi, penyaringan, pemisahan, dan dapat digunakan sebagai katalis (Bansal et al., 1988).

Penelitian di atas menunjukkan bahwa kulit pisang sangat potensial digunakan sebagai adsorben. Tujuan penelitian inimembuatkarbon aktif kulit pisang Goroho yang teraktivasi $\mathrm{H}_{2} \mathrm{SO}_{4}$ dan $\mathrm{NaOH}$ yang mampu menyerap zat warna Methylene Blue (MB) serta menentukan jenis aktivator, waktu kontak dan massa karbon aktif optimum terhadap penyerapan zat warna MB. Digunakannya zat warna MB sebagai sampel pada penelitian ini karena zat warna ini paling sering dipakai dalam industri tekstil, sutra, wool dan kosmetik. Mengingat besarnya dampak yang ditimbulkan dari zat warna sintetik, maka diperlukan suatu upaya untuk mengurangi dampak pencemaran dari zat warna tersebut.

\section{Material dan Metode}

\section{Alat dan Bahan}

Sampel yang digunakan adalah kulit pisang Goroho yang diambil dari pedagang gorengan yang berada di daerah sekitar kampus. Bahan kimia yang digunakan yaitu, $\mathrm{NaOH}, \mathrm{H}_{2} \mathrm{SO}_{4}$ danMethylene Blue. Peralatan yang digunakan adalah spektrofotometer UV-Vis (Shimadzu UV-1800), oven (Memmert), centrifuge (Gemmy PLC - 025), timbangan analitik (Adam PW 254), tanur, cawan porselin, lumpang, alu, kertas saring, $\mathrm{pH}$ meter dan alat-alat gelas (Iwaxi Pyrex).

\section{Preparasi Sampel}

Preparasi sampel kulit pisang Goroho mengikuti prosedur dari Fitriani et al. (2015) yang dimodifikasi. Sampel limbah kulit pisang diambil dari pedagang gorengan pisang Goroho. Kulit pisang dicuci bersih dengan air mengalir dan aquades untuk menghilangkan kotoran yang melekat pada kulit pisang sehingga kulit pisang benar-benar bersih. Lalu kulit pisang goroho dipotong kecil-kecil dengan ukuran 1-2 cm dan kemudian dijemur dibawah sinar matahari selama 2 hari.

\section{Pembuatan Karbon Aktif}

Pembuatan karbon aktif berikut ini merupakan prosedur dari Darmayanti et al. (2012) yang telah dimodifikasi. Kulit pisang Goroho yang telah dijemur hingga kering udara tersebut dikarbonisasi pada suhu $400^{\circ} \mathrm{C}$ selama $\pm 1,5$ jam. Kulit pisang Goroho tersebut ditumbuk halus untuk mendapatkan ukuran yang seragam. Setelah ditumbuk, direndam masing-masing dengan aktivator $\mathrm{NaOH}$ dan $\mathrm{H}_{2} \mathrm{SO}_{4}$ selama 1,5 jam. Kemudian dikeringkan dalam oven pada suhu $110^{\circ} \mathrm{C}$. Karbon aktif tersebut dicuci dalam aquades, disaring dan karbon aktifnya dikeringkan kembali selama 2 jam dalam oven.

\section{Uji Adsorpsi Karbon Aktif Kulit Pisang Goroho terhadap Zat Warna Methylene Blue}

Uji adsorpsi terhadap zat warna Methylene Blue berikut ini mengikuti prosedur Fitriani et al. (2015) yang dimodifikasi. Sebanyak 0,01 gram karbon aktif $\mathrm{H}_{2} \mathrm{SO}_{4}$ direndam dalam larutan Methylene Blue 5 ppm sebanyak $25 \mathrm{~mL}$ selama 10 menit (waktu kontak). Selanjutnya larutannya disentifugasi dan bagian filtratnya dianalisa dengan spektrofotometer UV-Vis pada panjang gelombang $664 \mathrm{~nm}$ untuk mengetahui adsorbansinya sehingga dapat diketahui konsentrasinya. Untuk prosedur yang sama dilakukan untuk variasi jenis aktivator $\mathrm{NaOH}$, massa adsorben karbon aktif $(0,03,0,05$ dan 0,10 gram) dan waktu kontak $(10,30,60,90$ dan 120 menit). Konsentrasi zat warna Methylene Blue setelah ditambahkan karbon aktif, biasa ditentukan dengan menggunakan persamaan regresi kurva standar yang diperoleh dengan membuat grafik hubungan antara konsentrasi dengan absorbansi. Sehingga diperoleh persamaan regresi yaitu, $y=$ $0,1466 x+10^{-16}$ dengan $R^{2}=0,994$.

Penentuan Efisiensi Penyerapan Karbon Aktif Kulit Pisang Goroho terhadap Zat Warna Methylene Blue

Penentuan efisiensi penyerapan karbon aktif mengikuti prosedur Agustina (2014). Efisiensi penyerapan (\% Teradsorpsi) karbon aktif kulit pisang Goroho terhadap zat warna Methylene Blue ditentukan menggunakan persamaan di bawah ini :

$$
\% \text { Teradsorpsi }=\left(\frac{\mathrm{C}_{\mathrm{o}}-\mathrm{C}_{\mathrm{t}}}{\mathrm{C}_{\mathrm{o}}}\right) \times 100 \%
$$

Dimana $\mathrm{C}_{0}$ adalah konsentrasi awal dan $\mathrm{C}_{\mathrm{t}}$ adalah konsentrasi setelah penambahan karbon aktif.

\section{Hasil dan Pembahasan \\ Pembuatan Karbon Aktif Kulit Pisang Goroho}

Kulit pisang Goroho (basah) yang digunakan sebanyak $1 \mathrm{~kg}$. Setelah dijemur di bawah matahari selama 2 hari menghasilkan berat kulit pisang Goroho kering seberat 149,46 gram. Selanjutnya, kulit pisang yang telah kering ini dikarbonisasi pada suhu $400^{\circ} \mathrm{C}$ selama 1,5 jam menghasilkan serbuk karbon seberat 36,33 gram.

Penyerapan Karbon Aktif Kulit Pisang Goroho Teraktivasi $\mathrm{H}_{2} \mathrm{SO}_{4}$ Terhadap Zat Warna Methylene Blue

Jumlah zat warna Methylene Blue yang teradsorpsi oleh 0,01, 0,03, 0,05 dan 0,10 gram karbon aktif kulit pisang Goroho teraktivasi $\mathrm{H}_{2} \mathrm{SO}_{4}$ 
pada konsentrasi awal Methylene Blue $5 \mathrm{ppm}$ disajikan pada Gambar 1.

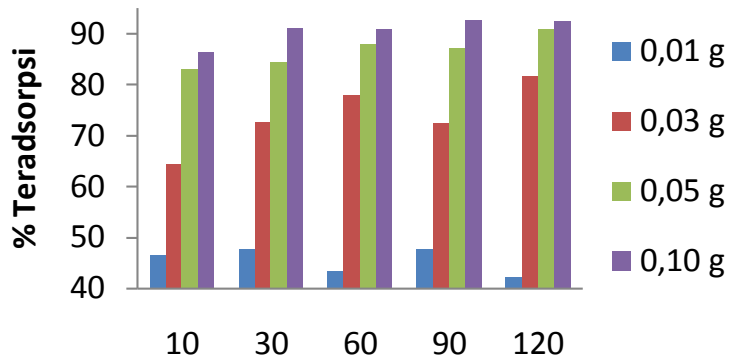

Waktu Kontak (menit)

Gambar 1. Jumlah Zat Warna Methylene Blue yang Teradsorpsi (\%) Karbon Aktif Kulit Pisang Goroho teraktivasi $\mathrm{H}_{2} \mathrm{SO}_{4}$

Gambar 1 menunjukkan bahwa massa 0,01 gram karbon aktif kulit pisang Goroho teraktivasi $\mathrm{H}_{2} \mathrm{SO}_{4}$ memiliki kemampuan mengadsorpsi zat warna Methylene Blue. Namun, kemampuan untuk mengadsorpsinya tidak lebih dari 50\% dari jumlah zat warna Methylene Blue. Besarnya persen teradsorpsi untuk tiap waktu kontak cenderung naik turun Methylene Blue. Hal ini diduga karena jumlah karbon aktif yang masih terlalu sedikit untuk penyerapan zat warna. Selanjutnya, ketika massa karbon aktif ditingkatkan hingga 0,03 gram terjadi peningkatan kemampuan adsorpsi zat warna Methylene Blue oleh karbon aktif kulit pisang Goroho yang mencapai persentase melebihi 50\%.

Adapun persentase tertinggi Methylene Blue yang teradsorpsi oleh 0,03 gram karbon aktif kulit pisang Goroho teraktivasi $\mathrm{H}_{2} \mathrm{SO}_{4}$ adalah 81,72\% pada waktu kontak 120 menit. Tampak bahwa persen teradsorpsi cenderung naik dari waktu kontak 10 menit hingga 60 menit dan turun pada saat waktu kontak 90 menit. Pada saat 120 menit, persen teradsorpsi naik kembali dan mencapai yang tertinggi. Pada saat massa karbon aktif yang ditambahkan sebesar 0,05 gram, persentase penyerapan terhadap Methylene Blue relatif meningkat dibandingkan bila menggunakan massa karbon aktif 0,03 gram untuk tiap waktu kontak. Seperti halnya pada 0,03 gram, besarnya persen teradsorpsi cenderung naik dari waktu kontak 10 menit hingga 60 menit. Selanjutnya turun pada waktu kontak 90 menit dan naik kembali pada waktu 120 menit yang merupakan persentase tertinggi, yaitu 90,86\%. Persen teradsorpsi terus meningkat ketika massa karbon aktif yang ditambahkan hingga 0,10 gram. Tampak bahwa persen teradsorpsinya Methylene Blue oleh karbon aktif untuk massa yang digunakan disini relatif lebih besar dibandingkan dengan penggunaan massa karbon kurang dari 0,10 gram untuk tiap waktu kontak.

Berdasarkan Gambar 1, dapat dilihat bahwa peningkatan persentase Methylene Blue yang terserap oleh karbon aktif kulit pisang Goroho teraktivasi $\mathrm{H}_{2} \mathrm{SO}_{4}$ dipengaruhi oleh jumlah massa karbon aktif yang ditambahkan dan waktu kontaknya terhadap zat warna Methylene Blue. Karbon aktif kulit pisang Goroho dengan massa 0,10 gram mencapai penyerapan zat warna Methylene Blue tertinggi dibandingkan karbon aktif dengan massa 0,01, 0,03 dan 0,05 gram, dengan waktu kontak terbaik pada menit ke 90 dan persentase penyerapannya mencapai hingga 92,63\%.

\section{Penyerapan Karbon Aktif Kulit Pisang Goroho Teraktivasi $\mathrm{NaOH}$ Terhadap Zat Warna Methylene Blue}

Jumlah zat warna Methylene Blue yang teradsorpsi oleh 0,01, 0,03, 0,05 dan 0,10 gram karbon aktif kulit pisang Goroho teraktivasi $\mathrm{NaOH}$ pada konsentrasi awal Methylene Blue 5 ppm disajikan dalam Gambar 2.

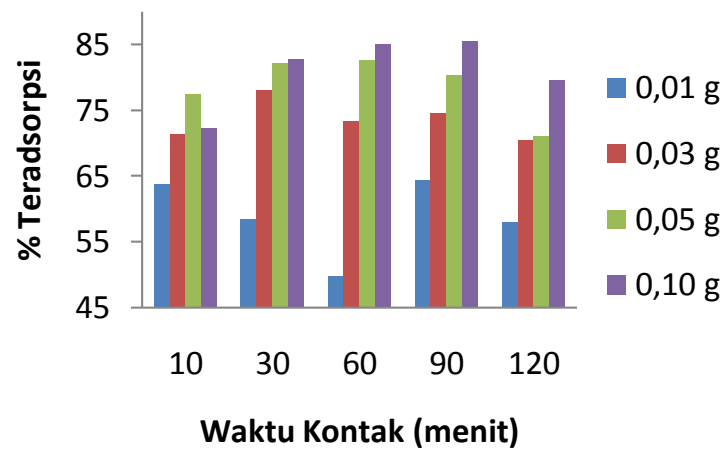

Gambar 2. Jumlah Zat Warna Methylene Blue yang

Teradsorpsi (\%) Karbon Aktif Kulit Pisang Goroho teraktivasi $\mathrm{NaOH}$

Pada Gambar 2 dapat dilihat bahwa massa 0,01 gram karbon aktif kulit pisang Goroho teraktivasi $\mathrm{NaOH}$ memiliki kemampuan mengadsorpsi lebih dari 50\% jumlah zat warna Methylene Blue. Persentase penyerapan tertinggi ada waktu kontak 90 menit, yaitu mencapai $64,25 \%$. Ketika massa karbon aktif ditingkatkan hingga 0,03 gram, terjadi peningkatan kemampuan adsorpsi zat warna Methylene Blue oleh karbon aktif kulit pisang Goroho yang mencapai persentase penyerapan zat warna melebihi $70 \%$. Adapun persentase tertinggi Methylene Blue yang teradsorpsi oleh 0,03 gram karbon aktif kulit pisang Goroho teraktivasi $\mathrm{NaOH}$ adalah $78,03 \%$ pada waktu kontak 30 menit.

Peningkatan persentase Methylene Blue yang teradsorpsi dapat mencapai 82,54\% (pada waktu kontak 60 menit) ketika massa karbon aktifnya sebesar 0,05 gram. Namun dapat dilihat bahwa pada menit ke 120, persentase penyerapannya menurun hingga $71,07 \%$. Hal ini diduga karena jumlah karbon aktif yang ditambahkan sudah melampaui massa optimum penyerapannya. Penyerapan 0,10 gram karbon aktif kulit pisang Goroho teraktivasi $\mathrm{NaOH}$ mampu menyerap hingga $85,54 \%$ zat warna Methylene Blue. Pada kondisi ini, persen teradsorpsi tertinggi terjadi pada waktu kontak 90 menit. 
Persentase Methylene Blue yang terserap oleh karbon aktif kulit pisang Goroho teraktivasi $\mathrm{NaOH}$ dipengaruhi oleh jumlah massa karbon aktif yang ditambahkan dan waktu kontaknya terhadap zat warna Methylene Blue.

Karbon aktif kulit pisang Goroho dengan massa 0,10 gram mencapai persentase penyerapan zat warna Methylene Blue tertinggi, yaitu $85,54 \%$ pada waktu kontak 90 menit. Bila dibandingkan dengan penggunaan karbon aktif teraktivasi $\mathrm{H}_{2} \mathrm{SO}_{4}$, karbon aktif yang diaktivasi dengan asam menghasilkan persen teradsorpsi yang lebih tinggi dibanding karbon aktif teraktivasi basa, yaitu 92,63\% pada massa 0,10 gram dan waktu kontak 90 menit. Ini menunjukkan bahwa zat warna Methylene Blue teradsorpsi lebih banyak ketika menggunakan karbon aktif teraktivasi asam dibandingkan karbon aktif teraktivasi basa untuk tiap waktu kontak. Sehingga berdasarkan hasil persentase penyerapan Methylene Blue tertinggi, diperoleh jenis aktivator terbaik yaitu $\mathrm{H}_{2} \mathrm{SO}_{4}$, massa karbon aktif terbaik pada 0,10 gram dan waktu kontak terbaik pada 90 menit untuk karbon aktif teraktivasi $\mathrm{H}_{2} \mathrm{SO}_{4}$ dan $\mathrm{NaOH}$. Menurut Mopoung (2008) dan Wulandari et al. (2015), daya jerap karbon aktif yang teraktivasi $\mathrm{NaOH}$ lebih rendah dibandingkan karbon aktif teraktivasi asam kuat $\mathrm{H}_{2} \mathrm{SO}_{4}$ dikarenakan $\mathrm{NaOH}$ bersifat basa kuat yang korosif sehingga menghasilkan banyak abu yang terlepas dari karbon. Karbon aktif dengan aktivator asam kuat lebih baik dibandingkan dengan aktivator basa kuat karena asam kuat memiliki struktur pori yang lebih kecil daripada basa kuat yang menyebabkan luas permukaannya semakin besar, sehingga daya jerapnya juga bertambah.

\section{Kesimpulan}

Dari hasil penelitian disimpulkan bahwa, kulit pisang Goroho dapat dibuat menjadi karbon aktif dengan menggunakan aktivator asam kuat $\mathrm{H}_{2} \mathrm{SO}_{4}$ dan basa kuat $\mathrm{NaOH}$. Berdasarkan hasil persentase penyerapan Methylene Blue, hasil tertinggi yaitu 92,63\% untuk karbon aktif kulit pisang Goroho teraktivasi $\mathrm{H}_{2} \mathrm{SO}_{4}$ dan 85,54\% untuk karbon aktif kulit pisang Goroho teraktivasi $\mathrm{NaOH}$ pada massa 0,10 gram dan waktu kontak 90 menit. Sehingga diperoleh jenis aktivator terbaik yaitu $\mathrm{H}_{2} \mathrm{SO}_{4}$, massa karbon aktif terbaik pada 0,10 gram dan waktu kontak terbaik pada 90 menit untuk karbon aktif teraktivasi $\mathrm{H}_{2} \mathrm{SO}_{4}$ dan $\mathrm{NaOH}$.

\section{Daftar Pustaka}

Agustina, V. 2014. Pemanfaatan Karbon Aktif dari Tempurung Kelapa Sebagai Adsorben Logam Pb pada Limbah Tumpahan Minyak Mentah (Crude Oil) [skripsi]. TK PNS, Palembang.

Alhabsyi, D. F., E. Suryanto., dan D. S. Wewengkang. 2014. Aktivitas Antioksidan dan Tabir Surya Pada Ekstrak Kulit Buah Pisang Goroho (Musa acuminateL.). Jurnal IImiah Farmasi - UNSRAT. 3(2) : 107-114.

Bansal, C. R., J. B. Donnet., and F. Stoecli. 1988. Active Carbon. Marcel Dekker Inc, New York.
Darmayanti., N. Rahman., dan Supriadi. 2012. Adsorpsi Timbal (Pb) dan Zink (Zn) dari Larutannya Menggunakan Arang Hayati (Biocharcoal) Kulit Pisang Kepok Berdasarkan Variasi pH. Jurnal Akademik Kimia. 1(4): 159165.

Fitriani, D., D. Oktiarni., dan Lusiana. 2015. Pemanfaatan Kulit Pisang Sebagai Adsorben Zat Warna Methylene Blue. Jurnal Gradien. 11(2) : 1091-1095.

Lubis, Z. 2012. Pengaruh Penambahan Tepung Kulit Pisang Raja (Musa paradisiaca) Terhadap Daya Terima Kue Donat. USU, [Medan].

Mopoung, S. 2008. Surface Image of Charcoal and Activated Charcoal from Banana Peel. Journal of Microsopy Society of Thailand. 22 : 15-19.

Pankaj, B. T., S. Ghoyal., dan P.K. Patnala.2012. A comparative Study of Sonosorption of Reactive Red 141 Dye on $\mathrm{TiO}_{2}$, Banana Peel, Orange Peel and Hardwood Saw Dust. Journal Applicable Chemistry. 1(4) : 505-511.

Wulandari, F., Umiatin., dan Esmar, B. 2015. Pengaruh Konsentrasi Larutan $\mathrm{NaOH}$ Pada Karbon Aktif Tempurung Kelapa Untuk Adsorpsi Logam $\mathrm{Cu}^{2+}$. Jurnal Fisika dan Aplikasinya. 16(2) : 60-64. 